Nat. Hazards Earth Syst. Sci., 19, 2879-2885, 2019

https://doi.org/10.5194/nhess-19-2879-2019

(C) Author(s) 2022. This work is distributed under

the Creative Commons Attribution 4.0 License.

\title{
Brief communication: Post-wildfire rockfall risk in the eastern Alps
}

\author{
Sandra Melzner ${ }^{1}$, Nurit Shtober-Zisu ${ }^{2}$, Oded Katz $^{3}$, and Lea Wittenberg ${ }^{4}$ \\ ${ }^{1}$ Geoconsult Holding ZT GmbH, Hölzlstraße 5, Wals bei Salzburg, 5071, Austria \\ ${ }^{2}$ Department of Israel Studies, University of Haifa, 199 Abba Khoushy Ave., Haifa, 3498838, Israel \\ ${ }^{3}$ Geological Survey of Israel, 32 Yesha'ayahu Leibowitz St., Jerusalem, 9692100, Israel \\ ${ }^{4}$ Department of Geography and Environmental Studies, University of Haifa, 199 Abba Khoushy Ave., Haifa, 3498838, Israel
}

Correspondence: Sandra Melzner (sandra.melzner@geoconsult.eu)

Received: 18 July 2019 - Discussion started: 29 July 2019

Revised: 31 October 2019 - Accepted: 12 November 2019 - Published: 19 December 2019

\begin{abstract}
In the eastern Alps, no previous research focused on the impact of wildfires on the occurrence of rockfalls. The investigation of wildfires and post-wildfire rockfalls gains new importance with respect to changes in weather extremes and rapid social developments such as population growth and tourism. The present work describes a wildfire that occurred in August 2018 in a famous world heritage site in Austria. Indicators of fire severity and rockfall occurrence during and after the fire are described.
\end{abstract}

\section{Introduction}

Many areas in the eastern Alps are prone to rockfalls endangering settlements and infrastructure, causing several fatalities every year. In recent years, wildfires in the Alps and their impact on the environment have gained new importance with respect to climate change and rapid social developments such as population growth and tourism.

Most research on the impact of wildfires has been done in the USA and the Mediterranean-climate region (Cerdà, 1998; Cerdà and Doerr, 2005; Parise and Cannon, 2012). Although post-wildfire risk from debris flows have been studied by various authors (Marxer et al., 1998; Conedera et al., 2003; Calcaterra et al., 2007; Cannon et al., 2010; Santi et al., 2013), rockfalls associated with wildfires have been poorly studied (Swanson, 1981; De Graff and Gallegos, 2012; Santi et al., 2013; De Graff et al., 2015). De Graff et al. (2015) showed that out of 16 wildfires in California (USA), seven wildfire-affected areas experienced significant rockfall occurrence days after the burn. The slope steepness and underlying lithology were given, showing maximum sizes from
$0.30-1.85 \mathrm{~m}$ in their largest dimension with an average of $0.5 \mathrm{~m}$. Furthermore, all rockfalls were generated from steep slopes (over $39^{\circ}$ ) of metasedimentary or granitic lithology experiencing moderate-to-high soil burn severity.

According to Keeley (2009) the term "fire intensity" is defined as the energy output from fire, whereas the terms "fire severity" and "burn severity" are used interchangeably for the aboveground and belowground organic matter consumption from fire. The term "ecosystem response" is defined as the functional processes that are altered by fire including regeneration, recolonization by plants and animals, and watershed. According to Keeley (2009) "soil burn severity" is often used interchangeably with "fire severity". In the USA, it is the preferred term (applied to soils) used in post-fire Burned Area Emergency Response assessments (Parson et al., 2010). Fire severity, however, is a more comprehensive term that also references "vegetation burn severity".

The aim of this work is to describe the impact of a wildfire which occurred in August 2018 at a steep rock wall in the heavily toured world heritage site "Hallstatt" in the Salzkammergut region in Upper Austria $\left(47^{\circ} 33^{\prime} 27.00^{\prime \prime} \mathrm{N}\right.$, $13^{\circ} 38^{\prime} 37.03^{\prime \prime} \mathrm{E}$ ). In order to assess the impact of the wildfire on the recent and future rockfall activity in the area, a helicopter flight and field survey were carried out. The survey was conducted by Sandra Melzner of the Geological Survey of Austria as part of the project "Georisks Austria" (GEORIOS). The focus of the inspection was on the identification of possibly changed potential rockfall areas and loosening of the rock due to the strong heat effect (Melzner, 2018) with regards to the rockfall hazard analysis conducted in 2014 (Melzner, 2015). The area was revisited conducted 
in May 2019 to record the temporal post-wildfire changes to the ecosystem.

\section{Wildfire-affected site}

\subsection{Area settings}

The wildfire site is situated on the southwest exposed rock walls of a glacially over-steepened Alpine trough valley. The valley is characterized by almost vertical rock walls several hundred metres high, which are mainly made of Mesozoic limestone (Dachstein Formation). The limestone is characterized by predominantly thick bedding, sudden changes in the joint mass structures and the presence of dominant fault systems. In the wildfire-affected part of the rock wall, the bedding has a predominantly medium steep dipping of 35 to $45^{\circ}$ in the direction of the rock wall (from northeast to northwest) (Melzner, 2015, 2018). The bedding planes form locations preferable for trees to grow and are usually covered with a thin layer of debris (Fig. 1). A fixed-rope climbing tour is installed in the rock wall, which is frequently used by numerous climbing tourists. The talus slope below the rock wall is relatively short and has an inclination between 30 and $40^{\circ}$. The soil type consists of scree $(\varnothing \lesssim 10 \mathrm{~cm})$ or medium compact soil with small rock fragments and some larger blocks. The scree is covered by a very thin layer of soil and organic matter which can be classified as brown rendzina and brown earth (Fig. 2). The vegetation is characterized by coniferous trees, mainly spruces and broad-leaved trees such as beech and larches. The pre-fire vegetation was composed of medium old forest and an understory of sparse bushes on the rockfall talus slope. The forest on the talus slope beneath the rock wall is designated as a protection forest for the houses in the valley floor. The annual precipitation is about $1743 \mathrm{~mm}$. The highest $1 \mathrm{~d}$ precipitation amount since 1901 was measured on 12 August 1959 to be $118 \mathrm{~mm}$, and the maximum annual precipitation measured was $2085 \mathrm{~mm}$ (1954). There are 20 to 30 convective summer thunderstorm days per year. Precipitation as snow occurs normally between November to April during which snow cover can reach thicknesses up to a few metres.

\subsection{Event description}

On 21 August 2018 at 09:30 LT a wildfire was presumably initiated by a carelessly discarded cigarette or the reflection of a broken glass bottle at the foot of the rock wall. At that time there were three groups of about 20 climbers on the via ferrata. Since the fire could only be extinguished from the air by helicopters, the via ferrata had to be evacuated to protect the climbers from falling rocks and branches caused by the downwind of the helicopters while fighting the fire. The fire rapidly spread up the rock wall (area size of about $3 \mathrm{ha}$ ) affecting the trees growing mainly on the bedding planes of the limestone (Fig. 1). The protection forest beneath the rock
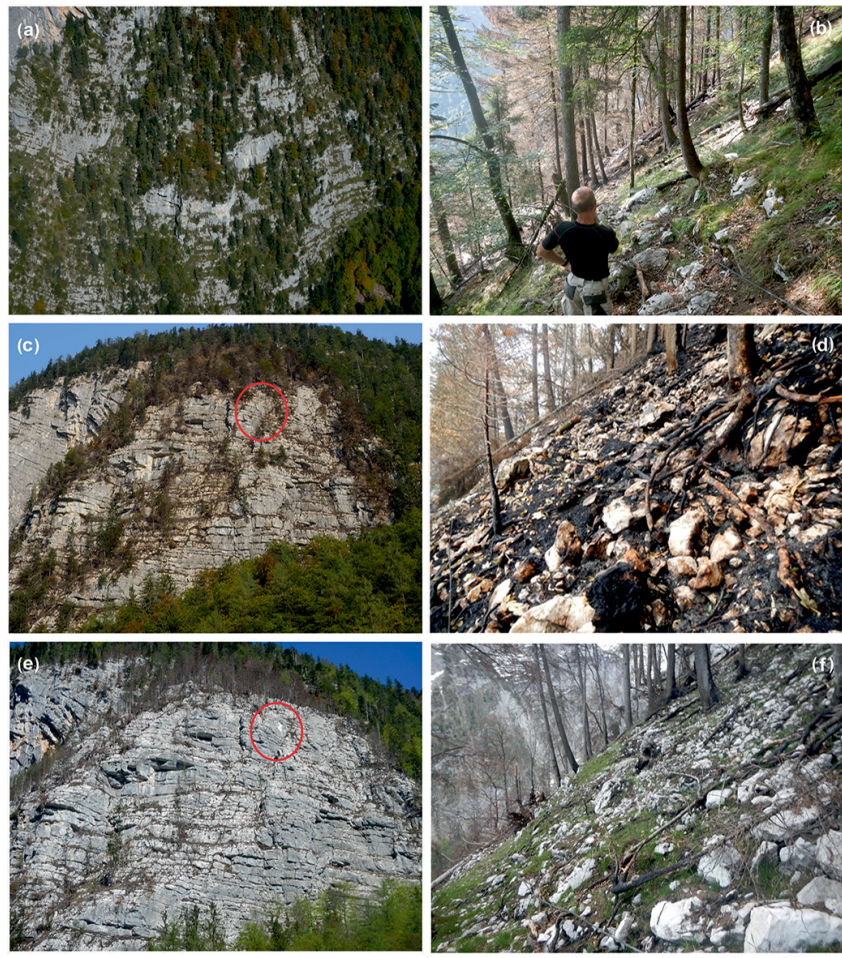

Figure 1. Temporal changes of the wildfire affected area: biomass, soil and rock characteristics before the wildfire in 2014 (a), in the border between burned and not-burned forest in August 2018 (b), directly after the wildfire in August 2018 (c, d), and 8 months after the burn in April 2019 (e, f). Post-wildfire rockfalls (red circle in e) with a volume of about a few cubic metres are recognizable.

wall was not affected by the fire (Fig. 2). During the night of 21 to 22 August the first evacuations of the houses beneath the rock wall took place as burned trunks, rootstocks and rock blocks were falling down the rock wall, the latter approaching two houses. Sixteen mapped rockfall boulders which reached the settlement area had volumes smaller than $0.3 \mathrm{~m}^{3}$ (Fig. 3). With the exception of minor damage to one building, no severe damage to buildings occurred, and local inhabitants were not injured. In the following days the firefighter brigades tried to extinguish the fire from above the rock wall with fire hoses and from the air with helicopters carrying water containers and buckets. In total, four police and military helicopters were flying during the days of the fire, refilling the buckets with water from the nearby Lake Hallstatt every two minutes. During the $4 \mathrm{~d}$ of the firefighting operation, up to 100 people (firefighters, police officers, military personnel and mountain rescue team members) were on duty every day. Unusual low-wind conditions and rainfall (starting on 24 August 2018) prevented the spread of the fire towards the village of Hallstatt. The official end of the firefighting mission was on 28 August 2018. A rockfall hazard and risk assessment conducted by the Geological Survey of Austria (Melzner, 2015) formed an important part of the 

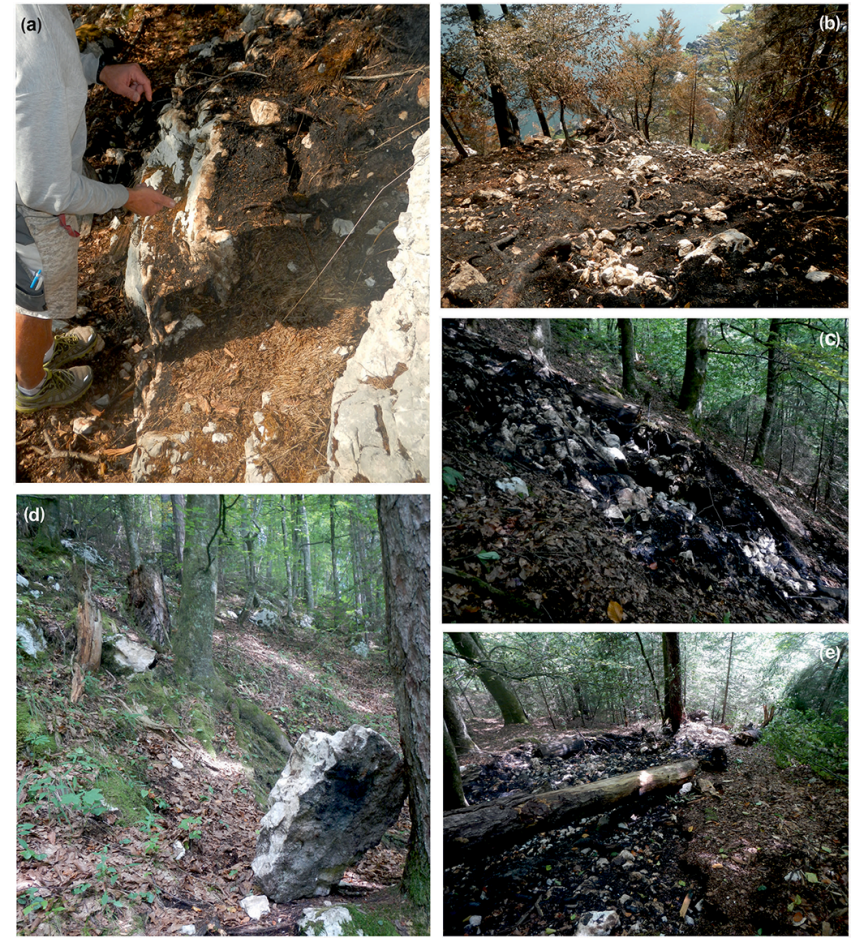

Figure 2. Indication of wildfire severity. (a) Crack development in the scree. (b) Ash and needles cover the terrain with a "sealing effect" reducing the infiltration capacity. (c) Talus slope beneath the rock wall is covered by a thin soil layer. (d) Rockfall boulders detached during the wildfire are often easily identifiable by their black colour. (e) The protection forest beneath the rock wall only was affected to a very minor extent due to the anabatic winds and high moisture of the brown rendzina and brown earth.

wildfire emergency response. Preventive rockfall hazard actions by the Austrian Torrent and Avalanche Control (WLV) after the wildfire included the (i) establishment of temporary rockfall protection measures (embarkments and simple rockfall fences) in order to be able to clear the wildfire area, (ii) clearance of the wildfire area (removal of loose stones, boulders, trees at risk of falling, etc.), (iii) repair of preexisting rockfall protective structures damaged by the rockfall, and (iv) sowing of seeds in the wildfire-affected scree and soil.

\section{Fire severity measures}

\subsection{Loss and decomposition of organic matter}

Indicators of fire severity (Figs. 1 and 2) are the colour of the trees and the decomposition degree of the leaves and needles. Unaffected trees have a green and unaltered colour, whereas burned or heated trees are easily recognizable by their brown colour. Varying degrees of consumption of the needles and leaves and organic matter can be related to different classes of fire severity. According the classification
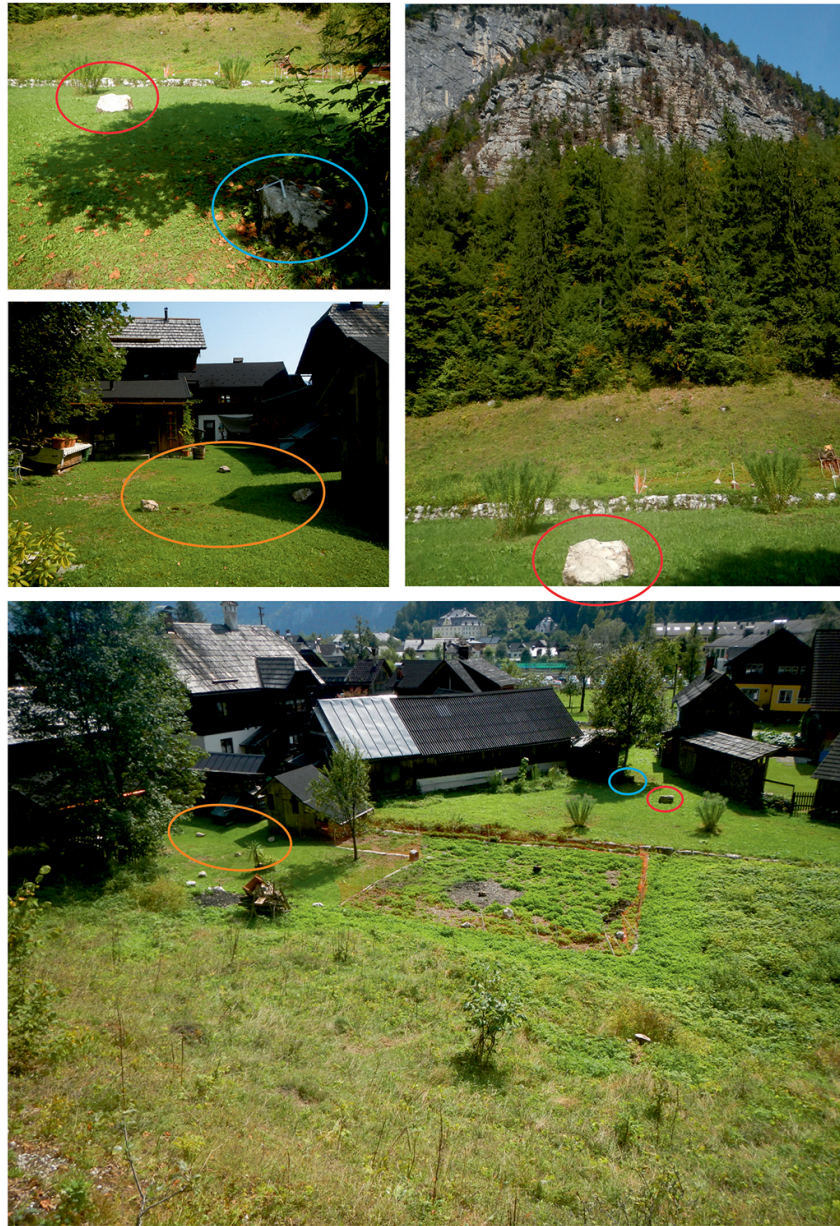

Figure 3. Rockfall boulders which were detached during the wildfire and reached the settlement area. An older rockfall boulder (blue circle) marks the maximum reach of past rockfalls and has a volume of about $0.2 \mathrm{~m}^{3}(0.8 \times 0.6 \times 0.4)$; the fresh boulder (red circle) has a volume of about $0.3 \mathrm{~m}^{3}(0.8 \times 0.75 \times 0.5)$.

of Keeley (2009), the trees in the affected area show moderate or severe surface burn. This is visible in that most of the burned trees still have needles, but all understorey plants and pre-fire soil organic layer (besides a post-wildfire needle cover) were consumed. In the transition area between the burned and not-burned areas, the vegetation shows indicators for light fire severity, expressed by green needles, although the stems may be scorched, and the understory plants and soil organic layer are largely intact. At the foot of the rock wall we observed a burning tree falling down the rock wall carrying a large rock, which burst into various rockfall boulders during the first impact with the ground.

\subsection{Changes in soil and rock mass structure}

The vertical relief of the rock walls, the anabatic winds and patchy vegetation pattern caused an upward jumping of the fire, resulting in a spotty fire pattern (Fig. 1). Thus, the res- 
idence time of the fire and the heating duration were reduced, leading to a less direct influence of the high temperatures on the rock mass structure. Fire-induced rock surface alteration and cracking due to thermal shock are typical rock-weathering processes occurring during a wildfire (Dorn, 2003; Shtober-Zisu et al., 2015). Thermal shock takes place when the thermally induced stress event is of sufficient magnitude to make the material unable to adjust quickly enough to accommodate the required deformation and accordingly fail (Hall, 1999). As a result, the surface failure takes the form of cracking or exfoliation due to the compression and the shear stress it induces (Yatsu, 1988). Moreover, rocks composed of several minerals, each with different coefficients of thermal expansion, may experience stresses resulting from the minerals' differential thermal response to the heating and cooling cycles (McFadden et al., 2005).

Spalling or the formation of exfoliation fissures (caused by insolation weathering) may be less severe in such exposedterrain conditions compared to more gentle slopes (Blackwelder, 1927; Zimmerman et al., 1994; Shakesby and Doerr, 2006; Shtober-Zisu et al., 2015). In the course of the wildfire, abundant small rock fragments had come to rest directly at the base of the rock wall. The rockfall boulders which were detached from the rock wall during the wildfire could be easily identified in the field, as they usually have at least one black (scorched) side (Fig. 2). Some smaller rockfall boulders with volumes of $<0.3 \mathrm{~m}^{3}$ have reached the valley floor (Fig. 3).

The slope in the uppermost part of the rock wall is covered by gravel, stones and blocks with a matrix composed of fine clastic material and ash. It could be mobilized in the form of a debris slide or flow in a heavy precipitation event. Such an event has not been documented thus far in this area. As the organic material mantling the scree slope in the upper part of the rock wall was consumed completely (Figs. 1 and 2), we observed that the ash covers the surface. Ash has a kind of "sealing effect" which reduces the infiltration, accelerates the splashing effect and increases the surface runoff (Brook and Wittenberg, 2016). It can be assumed that future frost and thaw cycles will further weaken the rock or that the loose slope debris in the upper-rock-wall area will be remobilized by heavy precipitation events. In forests, wildfire usually generates a mosaic of different levels of burn severity (Neary et al., 2005). In sites affected by fire of light-tomoderate severity, needle cast occurs when leaves from the scorched trees fall down and blanket the surface, thus protecting the soil from further erosion (Cerdà and Doerr, 2008; Robichaud et al., 2013). There are numerous studies addressing the effect of ash deposits on runoff and erosion processes, rates, and quality (Bodí et al., 2011). Results, however, are inconclusive; while many suggest that ash temporarily reduces infiltration, either by clogging soil pores or by forming a surface crust (Onda et al., 2008), others indicate that ash and specifically the black char produced during light-to-moderate fires might increase infiltration by storing rainfall and pro-

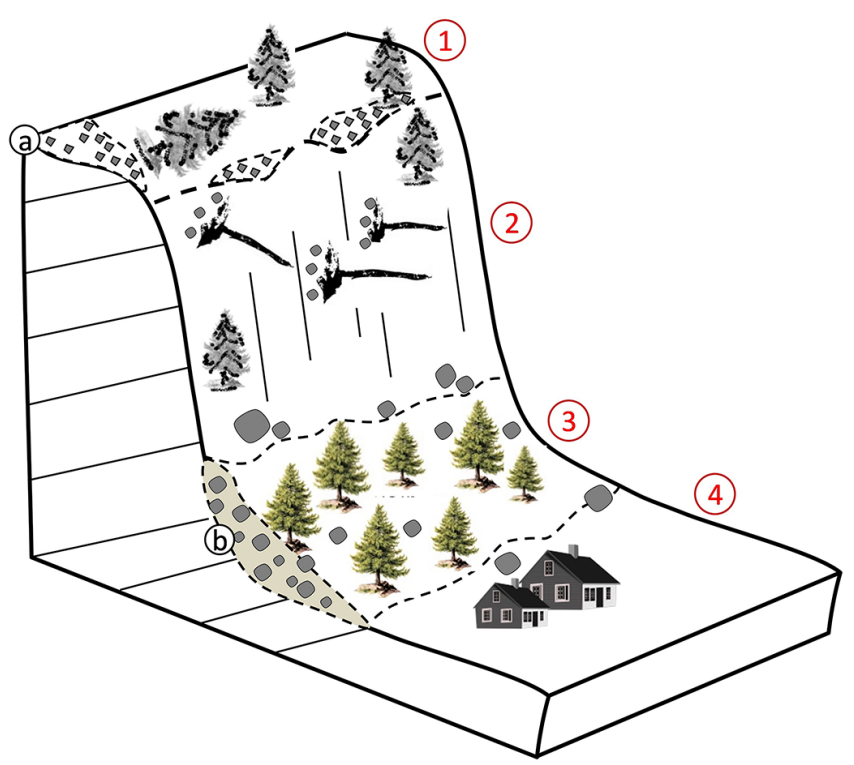

Figure 4. Sketch of the wildfire affected area. During the wildfire, the trees in the less inclined upper rock wall (1) and in the vertical rock wall (2) show indicators for medium fire severity; the protection forest (3) did not get affected by the wildfire. During the fire, rockfalls were detached from the rock face and by falling trees, which reached the houses in the valley floor (4). Scree is depicted in (a). Talus is depicted in (b).

tecting the underlying soil from sealing (Wittenberg, 2012). The ash layers may also protect the burned soil against raindrop impact and related splash erosion, and its leachates may reduce soil erodibility by promoting flocculation of the dispersed clays (Woods and Balfour, 2008). Ash particles penetrate, accumulate and shelter under the rock spalls formed during the fire, even for several decades (Shtober-Zisu et al., 2018).

\section{Post-wildfire rockfall risk}

Increased rockfall activity of rather smaller rock blocks is recognizable during as well as after the wildfire. The destabilization of small rock blocks and the burn of tree roots may also cause the destabilization of larger rock masses (Fig. 1). These would pose a significant risk to the houses and infrastructure. Above the steep rock wall, some greater boulders in and on top of the scree slope can be remobilized as secondary rockfalls by falling trees or undercutting erosional processes (Fig. 4).

The wildfire probably had a superficial impact on the rock mass structure of the vertical rock walls. According to Thomaz and Doerr (2014) moderate temperatures $\left(<400^{\circ} \mathrm{C}\right)$ had the most major effect on soil chemical properties. The study was conducted using a set of thermocouples that were placed at $0-2 \mathrm{~cm}$ soil depth. Even relatively low temperatures at the surface of the soil can trigger mineralogical changes. 
The burned roots in the joints and profound fractures accelerate physical weathering processes. The chemical weathering of rocks will speed their eventual transformation into secondary clay minerals causing slope instability due to it being a lower-strength material than the unweathered rock. The swelling potential of these secondary clays induce significant vertical overpressure, thus reinforcing subsequent progressive rockfall failure.

According to Bierman and Gillespie (1991), wildfires increase a rock's susceptibility to weathering through several mechanisms: (1) uneven heating and thermal expansion, along with the vaporization of endolithic moisture, induces spalling; (2) intense heating increases the rate of thermal diffusion significantly and accelerates the loss of gases such as argon, helium and neon from the rock; and (3) heating causes the microfracturing of rock and could cause the loss of chlorine-rich fluid from inclusions. Additionally, if the temperatures reached during the burning are high enough, decarbonation in the limestone may occur, enhancing decomposition and further erosion. If calcrete overtops the rock surface, its laminar structure substantially decreases the rocks' tensile strength and the threshold magnitude of the thermal stress needed to weather them. Thus, the laminar structure of the calcrete plays a key role in all types of physical weathering, specifically in the exfoliation process that occurs along the bedding planes between the laminae. The development of empirical relationships for predicting the location, magnitude and frequency of increased post-wildfire rockfall activity requires further research and the collection of more data. Although the mechanism of the direct and indirect impact of wildfire on debris flows has been studied in numerous past studies, knowledge about post-wildfire rockfalls is limited and is completely absent in the Alpine region. The observations in the present study imply that falling trees and burned roots might have a significant impact on rockfall occurrence during and after a wildfire event, but this issue requires further investigation. Rockfalls during the fire may be triggered by human activities such as firefighting or winds caused by helicopters during firefighting operations.

Vegetation recovery plays an important role in mitigating post-fire dynamics and increasing land stability. Rates and patterns of post-fire vegetation regeneration were extensively studied in the Mediterranean; however, Alpine vegetation has gained relatively little attention (Camac et al., 2013). In Austria, a study that documented patterns of post-fire land recovery indicated that 60 years after a fire trees covered only $40 \%$ of the burned area, whilst grassland and exposed rock and debris areas have expanded and remained active. Moreover, it was suggested that the slope will not reach its former condition before 2070 . This extreme window of disturbance of more than 120 years is attributed to the steepness of the slope and to the shallow soils and dolomitic bedrock that were severely damaged by the fire (Malowerschnig and Sass, 2014).

\section{Conclusions and recommendations}

In the eastern Alps, no work on wildfires and post-wildfire rockfall activity has been published so far. The August 2018 Hallstatt wildfire shows clearly that wildfires can have a significant impact on ecosystems and pose a high risk to settlements in the Alpine area. Wildfires in steep Alpine valleys behave differently than those in flat areas or on moderately inclined slopes. The vertical rock walls, the anabatic winds and patchy vegetation pattern caused an upward jumping of the fire resulting in a spotty fire pattern. This most probably results in spatially varying fire intensities and consequently highly heterogenic changes in the soil and rock mass structure. It makes it very difficult to predict future rockfall occurrences and estimate the associated risk. The rockfall hazard and risk assessment conducted in 2014 enabled fast decisionmaking as part of an emergency response during and after the wildfire catastrophe in terms of the identification of possibly endangered houses as well as the planning of preliminary rockfall preventive measures.

Future research activities should focus on the study of wildfire behaviour in Alpine valleys. A national wildfire database in combination with a forest inventory map would help to plan forest management strategies for wildfires in the Alpine region. The development of tools to identify the days of high wildfire risk supported by the meteorological survey would enable a fire hazard rating system. Despite the logistical difficulties in the highly exposed relief, there is a practical need to understand the wildfire-induced rock surface alteration and cracking due to thermal shock in order to improve the prediction of potential post-fire rockfall problems and associated hazards and risks. The compound impact of fire and snow cover on future rockfall and debris slide and flow activity would be a very important future research topic.

Data availability. Data are available upon request to the corresponding author.

Author contributions. SM conceptualized the study, collected data, prepared three of the figures and wrote the first draft of the paper. LW contributed to the drafting of the paper. NSZ prepared one of the figures and contributed to the drafting of the paper. OK edited the paper.

Competing interests. The authors declare that they have no conflict of interest.

Acknowledgements. The authors would like to thank the editor Mario Parise, the reviewer Jerome De Graff and a second anonymous reviewer for their constructive comments and suggestions regarding the paper. 
Review statement. This paper was edited by Mario Parise and reviewed by Jerome De Graff and one anonymous referee.

\section{References}

Bierman, P. and Gillespie, A.: Range fires: A significant factor in exposure-age determination and geomorphic surface evolution, Geology, 19, 641-644, 1991.

Blackwelder, E.: Fire as an Agent in Rock Weathering, J. Geol., 35, 134-140, https://doi.org/10.1086/623392, 1927.

Bodí, M. B., Mataix-Solera, J., Doerr, S. H., and Cerdà, A.: The wettability of ash from burned vegetation and its relationship to Mediterranean plant species type, burn severity and total organic carbon content, Geoderma, 160, 599-607, https://doi.org/10.1016/j.geoderma.2010.11.009, 2011.

Brook, A. and Wittenberg, L.: Ash-soil interface: Mineralogical composition and physical structure, Sci. Total Environ., 572, 1403-1413, https://doi.org/10.1016/j.scitotenv.2016.02.123, 2016.

Calcaterra, D., Parise, M., Strumia, S., and Mazella, E.: Relations between fire, vegetation and landslides in the heavily polulated metroplitan area of Naples, in: Proceedings 1st North American Landslide Conference, Vail, Colorado, 3-8 June 2007, edited by: Schaefer, V. R., Schuster, R. L., and Turner, A. K., AEG Special Publication 23, 1448-1461, 2007.

Camac, J. S., Williams, R. J., Wahren, C. H., Morris, W. K., and Morgan, J. W.: Post-fire regeneration in alpine heathland: Does fire severity matter?, Austral Ecoly, 38, 199-207, 2013.

Cannon, S. H., Gartner, J. E., Rupert, M. G., Michael, J. A., Rea, A. H., and Parrett, C.: Predicting the probability and volume of postwildfire debris flows in the intermountain western United States, GSA Bulletin, 122, 127-144, https://doi.org/10.1130/B26459.1, 2010.

Cerdà, A.: Changes in overland flow and infiltration after a rangeland fire in a Mediterranean scrubland, Hydrol. Process., 12, 1031-1042, https://doi.org/10.1002/(SICI)10991085(19980615)12:7<1031:AID-HYP636>3.0.CO;2-V, 1998.

Cerdà, A. and Doerr, S. H.: Influence of vegetation recovery on soil hydrology and erodibility following fire: an 11-year investigation, Int. J. Wildland Fire, 14, 423-437, https://doi.org/10.1071/WF05044, 2005.

Cerdà, A. and Doerr, S. H.: The effect of ash and needle cover on surface runoff and erosion in the immediate post-fire period, CATENA, 74, 256-263, https://doi.org/10.1016/j.catena.2008.03.010, 2008.

Conedera, M., Peter, L., Marxer, P., Forster, F., Rickenmann, D., and Re, L.: Consequences of forest fires on the hydrogeological response of mountain catchments: a case study of the Riale Buffaga, Ticino, Switzerland, Earth Surf. Proc. Land., 28, 117129, https://doi.org/10.1002/esp.425, 2003.

De Graff, J. and Gallegos, A.: The Challenge of Improving Identification of Rockfall Hazard after Wildfires, Environ. Eng. Geosci., 18, 389-397, https://doi.org/10.2113/gseegeosci.18.4.389, 2012.

De Graff, J., Shelmerdine, B., Gallegos, A., and Annis, D.: Uncertainty Associated with Evaluating Rockfall Hazard to Roads in Burned AreasRockfall Hazard in Burned Areas, Environ. Eng. Geosci., 21, 21-33, https://doi.org/10.2113/gseegeosci.21.1.21, 2015 .
Dorn, R. I.: Boulder weathering and erosion associated with a wildfire, Sierra Ancha Mountains, Arizona. Geomorphology, Mountain Geomorphology - Integrating Earth Systems, Proceedings of the 32nd Annual Binghamton Geomorphology Symposium 55, 155-171, https://doi.org/10.1016/S0169-555X(03)00138-7, 2003.

Hall, K.: The role of thermal stress fatigue in the breakdown of rock in cold regions, Geomorphology, 31, 47-63, 1999.

Keeley, J. E.: Fire intensity, fire severity and burn severity: a brief review and suggested usage, Int. J. Wildland Fire, 18, 116-126, https://doi.org/10.1071/WF07049, 2009.

Malowerschnig, B. and Sass, O.: Long-term vegetation development on a wildfire slope in Innerzwain (Styria, Austria), J. Forestry Res., 25, 103-111, 2014.

Marxer, P., Conedera, M., and Schaub, D.: Postfire runoff and soil erosion in the sweet chestnut belt of southern Switzerland, in: Fire Management and Landscape Ecology, edited by: Trabaud, L., International Association of Wildland Fire, Washington, 5162, 1998.

McFadden, L. D., Eppes, M. C., Gillespie, A. R., and Hallet, B.: Physical weathering in arid landscapes due to diurnal variation in the direction of solar heating, GSA Bulletin, 117, 161-173, https://doi.org/10.1130/B25508.1, 2005.

Melzner, S.: Einschätzung des Gefahrenpotentials durch Sturzprozesse als Folge des Waldbrandes (20.8.-25.8.2018) im Bereich der Echernwand/Hohe Sieg, Geological Survey of Austria, Vienna, Technical report, 16 pp., 2018.

Melzner, S.: Analyse des Gefahrenpotentials durch primäre Sturzprozesse (Steinschlag/Felssturz) - Gemeindegebiet Hallstatt, Geological Survey of Austria, Vienna, Technical report, 156 pp., 2015.

Neary, D. G., Ryan, K. C., and De Bano, L. F.: Wildland fire in ecosystems: effects of fire on soils and water, U.S. Department of Agriculture, Forest Service, Rocky Mountain Research Station, Ogden, UT, Gen. Tech. Rep. RMRS-GTR-42-vol.4, 250 pp., https://doi.org/10.2737/RMRS-GTR-42-V4, 2005.

Onda, Y., Dietrich, W. E., and Booker, F.: Evolution of overland flow after a severe forest fire, Point Reyes, California, CATENA, 72, 13-20, https://doi.org/10.1016/j.catena.2007.02.003, 2008.

Parise, M. and Cannon, S. H.: Wildfire impacts on the processes that gerate debris flows in burned watersheds, Nat. Hazards, 61, 217-227, 2012.

Parson, A., Robichaud, P. R., Lewis, S. A., Napper, C., and Clark, J. T.: Field guide for mapping post-fire soil burn severity, U.S. Department of Agriculture, Forest Service, Rocky Mountain Research Station, Gen. Tech. Rep. RMRS-GTR-243, 49 pp., https://doi.org/10.2737/RMRS-GTR-243, 2010.

Robichaud, P. R., Wagenbrenner, J. W., Lewis, S. A., Ashmun, L. E., Brown, R. E., and Wohlgemuth, P. M.: Post-fire mulching for runoff and erosion mitigation Part II: Effectiveness in reducing runoff and sediment yields from small catchments, Catena, 105, 93-111, https://doi.org/10.1016/j.catena.2012.11.016, 2013.

Santi, P., Cannon, S., and DeGraff, J.: 13.16 Wildfire and Landscape Change, in: Treatise on Geomorphology, edited by: Shroder, J. F., Academic Press, San Diego, 13, 262-287, https://doi.org/10.1016/B978-0-12-374739-6.00365-1, 2013.

Shakesby, R. A. and Doerr, S. H.: Wildfire as a hydrological and geomorphological agent, Earth-Sci. Rev., 74, 269-307, https://doi.org/10.1016/j.earscirev.2005.10.006, 2006. 
Shtober-Zisu, N., Tessler, N., Tsatskin, A., and Greenbaum, N.: Accelerated weathering of carbonate rocks following the 2010 wildfire on Mount Carmel, Israel, Int. J. Wildland Fire, 24, 1154 1167, https://doi.org/10.1071/WF14221, 2015.

Shtober-Zisu, N., Brook, A., Kopel, D., Roberts, D., Ichoku, C., and Wittenberg, L.: Fire induced rock spalls as long-term traps for ash, CATENA, 162, 88-99, https://doi.org/10.1016/j.catena.2017.11.021, 2018.

Swanson, F. J.: Fire and geomorphic process, Fire Regime and Ecosystem Properties, USDA Forest Serviece General Technical report WO-26, 1981.

Thomaz, E. L. and Doerr, S. H.: Relationship between fire temperature and changes in chemical soil properties: a conceptual model of nutrient release, EGU General Assembly 2014, Vienna, Austria, 27 April-2 May 2014, EGU2014-166, 2014.
Wittenberg, L.: Post-Fire Soil Ecology: Properties and Erosion Dynamics, Isr. J. Ecol. Evol., 58, 151-164, 2012.

Woods, S. W. and Balfour, V. N.: The effect of ash on runoff and erosion after a severe forest wildfire, Montana, USA, Int. J. Wildland Fire, 17, 535-548, https://doi.org/10.1071/WF07040, 2008.

Yatsu, E.: "The nature of weathering, An Introduction", Sozosha, Tokyo, 1988.

Zimmerman, S. G., Evenson, E. B., Gosse, J. C., and Erskine, C. P.: Extensive Boulder Erosion Resulting from a Range Fire on the Type-Pinedale Moraines, Fremont Lake, Wyoming, Quaternary Res., 42, 255-265, https://doi.org/10.1006/qres.1994.1076, 1994. 